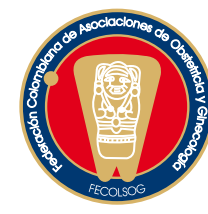

\title{
LEY DEL TALENTO HUMANO: UN GRAN MOMENTO PARA EL FORTALECIMIENTO DEL GREMIO DE LA SALUD
}

\section{The Law of Human Talent (Colombian Law 1164 , 2007): a great opportunity for the medical body to close ranks}

La promulgación de la Ley 100 tomó al gremio de trabajadores de la salud desprevenido, razón por la cual no se asumió una conducta correcta para el aprovechamiento de esta ley en beneficio del personal que labora en el área de la salud, en términos de: una mejor relación médico-paciente; una mayor capacitación y mejores condiciones laborales, de tal manera que estas desmejoraron; se debilitaron la relación autónoma entre el paciente y el médico, y las instituciones públicas de salud.

El pasado 3 de octubre, el Presidente de la República sancionó la Ley 1164 o Ley del Talento Humano en Salud, en esta oportunidad la comunidad médica está mejor preparada para su reglamentación, hecho que nos brinda la oportunidad de desarrollar nuestra actividad de manera adecuada, como profesionales altamente calificados, y mejorar nuestras condiciones de trabajo; esto se dará si y solo si continuamos apoyando la labor desarrollada por las sociedades científicas.

La Fecolsog, ha contribuido activamente para la reglamentación de esta ley, que nos permitirá: fortalecernos como gremio, participar de las decisiones en políticas de salud e influir en los programas de estudio y recertificación. Es muy importante continuar con esta labor ya que de lo contrario la ley podría convertirse en letra muerta o pasar a ser otro impuesto más para el sector cuando cada determinado tiempo tengamos que recertificarnos pagando sumas onerosas por cursos o exámenes requeridos para tal fin.

Participar en la reglamentación e impulsar que esta ley sea "actuante" nos permitirá a los gineco obstetras tener presencia en los organismos de apoyo para el desarrollo del talento humano en salud, como son: El Consejo Nacional del Talento Humano en Salud, a través de Sociedades Científicas y el Colegio Médico Colombiano, y participar en los comités de apoyo. Esta nueva ley nos permitirá recomendar al Ministerio de Educación los planes de los diferentes niveles de formación para el mejoramiento de la competencia, pertinencia, calidad, cantidad, contenidos e intensidad de los programas educativos en el área de la salud. La ley nos permitirá dar un concepto técnico acerca del manual de tarifas, basado en el riesgo y complejidad en la realización de los procedimientos y actividades, para que se haga un justo reconocimiento del trabajo médico.

Por otra parte, seremos los colegios de profesionales quienes expidamos la tarjeta profesional, los permisos transitorios para extranjeros en misión científica o humanitaria en nuestro país, y quienes establezcamos los criterios para la recertificación de los profesionales. Para esto se requiere establecer criterios claros, con flexibilidad suficiente, para que se le facilite igualmente a un ginecólogo de las principales ciudades o de cualquier otro lugar del país. Se deberá reglamentar adecuadamente la asistencia a las actua- 
lizaciones teóricas y prácticas, la disponibilidad de tecnologías para educación a distancia y la facilitación y validación de las publicaciones científicas, haciendo posible y viable la recertificación.

Este es el momento para rodear a las instituciones como el Colegio Médico Colombiano fortaleciéndolo para que la reglamentación de esta ley sea en beneficio del pueblo colombiano y de los trabajadores de la salud, para mejorar la calidad de los servicios de salud y la salud de nuestros pacientes.

Héctor Jaramillo Villarreal, M.D. Presidente Fecolsog 